\title{
Eficiência de radiação UV-C no controle da antracnose e da podridão peduncular em abacate 'Hass'
}

\author{
Ivan Herman Fischer ${ }^{1 *}$, Maria Cecília de Arruda Palharini ${ }^{1}$, Elisangela Marques Jeronimo ${ }^{1}$, Maria Márcia \\ Pereira Sartori ${ }^{2}$, Rosa Maria Valdebenito Sanhueza ${ }^{3}$
}

\begin{abstract}
RESUMO: Objetivou-se avaliar o efeito de doses de radiação UV-C na ocorrência de antracnose e de podridão peduncular em abacates 'Hass' com e sem inoculação com Colletotrichum gloeosporioides e Lasiodiplodia theobromae, em pós-colheita. A região peduncular dos frutos foi submetida às doses de radiação UV-C de 0,$36 ; 0,48$; 0,60 e $0,72 \mathrm{~kJ} \mathrm{~m}^{-2}$, enquanto a região equatorial foi exposta às doses de 0,$34 ; 0,45 ; 0,56$ e $0,67 \mathrm{~kJ} \mathrm{~m}^{-2}$. Após o armazenamento dos frutos a $6^{\circ} \mathrm{C}$ por 21 dias e mais seis ou oito dias a $21^{\circ} \mathrm{C}$, avaliou-se a incidência das doenças em frutos não inoculados e a incidência e a severidade da antracnose e da podridão de lasiodiplodia em frutos inoculados, medindo-se o diâmetro da lesão de antracnose na região equatorial e o comprimento da podridão de lasiodiplodia a partir do pedúnculo. Nos tratamentos sem inoculação, foram analisadas as variáveis firmeza da polpa, sólidos solúveis e acidez titulável. Os resultados foram submetidos à análise de variância e as médias comparadas pelo teste de Tukey (5\%). De maneira geral, as doses de radiação UV-C avaliadas não reduziram a ocorrência das doenças nos frutos com ou sem inoculação dos patógenos, assim como não afetaram as variáveis físico-químicas do abacate 'Hass'.
\end{abstract}

Palavras-chave: manejo de doenças, Persea americana, Colletotrichum, Lasiodiplodia

\section{Efficiency of UV-C radiation in the control of anthracnose and stem rot in avocado 'Hass'}

\begin{abstract}
The present project evaluated the effect of UV-C radiation doses on the occurrence of postharvest anthracnose and stem rot in 'Hass' avocados with and without inoculation with Colletotrichum gloeosporioides and Lasiodiplodia theobromae. The peduncle region of the fruits was submitted to UV-C radiation doses of 0.36; 0.48; 0.60 and $0.72 \mathrm{~kJ} \mathrm{~m}^{-2}$, and the equatorial region was exposed to UV doses of $0.34 ; 0.45 ; 0.56$ and $0.67 \mathrm{~kJ} \mathrm{~m}^{-2}$. After storage of the fruits at $6^{\circ} \mathrm{C}$ for 21 days and more six or eight days at $21^{\circ} \mathrm{C}$, the incidence of diseases in uninoculated fruits and the incidence and severity of the anthracnose and the lasiodiplodia rot in inoculated fruits were evaluated, considering the diameter of the anthracnose lesion in the equatorial region and the length of lasiodiplodia rot from the peduncle. In the treatments without inoculation, the variables firmness of the pulp, soluble solids and titratable acidity were evaluated. The results were submitted to analysis of variance and the means compared by the Tukey test (5\%). In general, the evaluated UV-C radiation doses did not reduce the occurrence of diseases in fruits with or without inoculation of the pathogens, nor did they affect the physical-chemical variables of 'Hass' avocado.
\end{abstract}

Keywords: disease management, Persea americana, Colletotrichum, Lasiodiplodia

\section{INTRODUÇÃO}

No cultivo comercial do abacateiro no Brasil as variedades podem ser agrupadas em tipo exportação ou consumo interno. As preferidas para consumo interno geralmente apresentam baixo teor de óleo e produzem frutos grandes. Para exportação, as variedades mais cultivadas são a Hass e a Fuerte, conhecidas popularmente como 'avocado', de tamanho pequeno e alto teor de óleo. $\mathrm{O}$ abacate 'Hass' tem apresentado produção crescente nos últimos anos, destinado principalmente para o mercado europeu. Esta variedade possui formato oval a piriforme, massa média entre 180 a 300 gramas, casca grossa, rugosa e de coloração verde na planta e imediatamente após a colheita, mas com o amadurecimento a coloração da casca muda para marrom escuro (SCHAFFER et al., 2013).

O abacate é um fruto climatérico, cujo amadurecimento ocorre poucos dias após a colheita, resultado de uma série de eventos, como aumento na atividade respiratória e na produção de etileno, e modificações no conteúdo lipídico, ocorrendo ainda mudanças na textura, envolvendo degradação de células do mesocarpo, redução no conteúdo de amido e aumento de glicose e frutose (SEYMOUR, TUCKER, 1993).

O abacateiro é afetado por diversas doenças que ocorrem em pré e em pós-colheita. A antracnose, causada por Colletotrichum gloeosporioides, é considerada a principal doença em pós-colheita, ocorrendo em todos os países produtores (DANN et al., 2013). Em abacates 'Hass' amostrados em packinghouse do estado de São Paulo, procedentes de diferentes pomares, a antracnose ocorreu em $56,4 \%$ dos frutos, na média de duas safras, variando de 27 a $81 \%$ em função da procedência, após 9 ou 12 dias de armazenamento a $25^{\circ} \mathrm{C}$ e $80-85 \%$ de UR (FISCHER et al., 2017). A infecção ocorre no campo durante o desenvolvimento do fruto pelas

\footnotetext{
Recebido em 15/10/2018; Aceito para publicação em 30/04/2019

${ }^{1}$ Agência Paulista de Tecnologia dos Agronegócios

${ }^{2}$ Universidade Estadual Paulista

${ }^{3}$ Proterra Consultoria Agronômica

*email: ihfische@apta.sp.gov.br
} 
lenticelas ou ferimentos do fruto e permanece quiescente até o amadurecimento por condições fisiológicas impostas pelo hospedeiro (DANN et al., 2013), de modo que os frutos são colhidos aparentemente sadios e manifestam os sintomas da doença apenas durante $\mathrm{o}$ armazenamento $\mathrm{e}$ comercialização. Sintomas nos frutos são característicos, iniciando-se por pequenas pontuações de coloração escura e formato circular. As lesões tendem a evoluir atingindo parte do fruto ou necrosando-o completamente (PICCININ et al., 2016).

Além da antracnose, diversas outras doenças podem afetar os abacates em pós-colheita (DANN et al., 2013). Em levantamento das podridões em abacates 'Hass' no estado de São Paulo, as podridões de lasiodiplodia, causada por Lasiodiplodia theobromae, e de fusicoccum, causada por Fusicoccum spp., atingiram 4 e 3\% dor frutos, respectivamente (FISCHER et al., 2011). Os sintomas nos frutos decorrentes das podridões de lasiodiplodia ou fusicoccum são semelhantes, e caracterizam-se por uma necrose escura na região do pedúnculo, avançando para todo o fruto, com produção de micélio acinzentado na superfície necrosada do fruto.

O controle das doenças pós-colheita baseia-se em adubações equilibradas do pomar; podas de limpeza, com a eliminação de ramos secos, debilitados e de frutos doentes; aplicação de fungicidas duas a três vezes no pomar, no período compreendido entre o florescimento e a frutificação (PICCININ et al., 2016). Entretanto, é difícil obter frutos livres da antracnose, mesmo após rigorosa aplicação dos fungicidas recomendados (DARVAS, 1981).

Para o controle das doenças em tratamento póscolheita de frutas existem práticas químicas, físicas e biológicas, as quais podem atuar diretamente nos patógenos e/ou na fisiologia dos frutos, retardando seu amadurecimento e aumentando sua resistência (SILVEIRA et al., 2011; NASCIMENTO et al., 2014). Os fungicidas imazalil, procloraz e tiabendazol são eficientes no controle pós-colheita das podridões em abacates (FISCHER et al., 2011). Entretanto, decorrente das crescentes restrições ao uso de fungicidas em pós-colheita, alguns países, como a França, não permitem o tratamento póscolheita com procloraz (SCHAFFER et al., 2013). Dentre os métodos alternativos viáveis e já testados em pós-colheita com eficiência comprovada para frutas, a aplicação de radiação UV-C apresenta efeito germicida direto sobre os microrganismos presentes na superfície irradiada e indireto, induzindo a resistência das plantas (PALOU, 2009). Cia et al. (2009) constataram que a radiação UV-C reduz a incidência da podridão-da-uva-madura em uvas 'Niágara Rosada' inoculadas com $C$. gloeosporioides. Estudos realizados em maçãs mostram que a radiação UV-C pode agir como indutor de resistência à podridão amarga causada pelo fungo C. gloeosporioides (STEVENS et al., 2005).

Controle de Cryptosporiopsis perennans, causador da podridão olho-de-boi (POB) em maçãs, foi obtido com $0,37 \mathrm{~kJ} \mathrm{~m}^{-2}$ de radiação UV-C (BARTNICKI et al., 2010). Em maçãs submetidas a $0,0069 \mathrm{~kJ} \mathrm{~m}^{-2}$ de radiação UV-C, aplicada em uma linha comercial de seleção em packinhouse, o controle da incidência da POB em maçãs 'Fuji' foi superior a $55 \%$ em frutos inoculados com o patógeno e superior a $64 \%$ em frutos com infecção natural (BARTNICKI et al., 2011), evidenciando sua aplicabilidade. $\mathrm{O}$ tratamento dos frutos com radiação UV-C tem a vantagem de não deixar resíduos indesejáveis nos frutos, além de não oferecer riscos à saúde humana e ao meio ambiente, podendo ser mais uma ferramenta a ser utilizada no controle integrado de doenças.

Em virtude da carência de informações sobre o manejo das doenças do abacate, objetivou-se avaliar o efeito de doses de radiação UV-C na incidência e na severidade de antracnose e podridão peduncular em frutos da variedade Hass, com e sem inoculação com C. gloeosporioides e L. theobromae.

\section{MATERIAIS E MÉTODOS}

Abacates 'Hass' foram colhidos nos meses de abril e junho de 2017, em pomar comercial localizado em Bauru-SP. O manejo das doenças adotado pelo produtor consistiu de uma aplicação de azoxistrobina+difenoconazol $\left(0,060+0,038 \mathrm{~g} \mathrm{~L}^{-1}\right)$ na formação dos cachos florais, em setembro de 2016, e duas aplicações sequenciais de oxicloreto de cobre $\left(2 \mathrm{~g} \mathrm{~L}^{-1}\right)$, em intervalos de aproximadamente 45 dias, durante a frutificação, empregando-se um volume de calda de $1250 \mathrm{~L} /$ hectare. Após a colheita, os frutos foram desinfetados com oxicloreto de cálcio $(0,182$ $\mathrm{g} \mathrm{L}^{-1}$ ), através de imersão em calda por 1 minuto.

Os isolados de $C$. gloeosporioides e $L$. theobromae foram obtidos por isolamento direto em meio batata-dextrose-ágar (BDA) de porções doentes de frutos de abacate com sintomas característicos de antracnose e podridão de lasiodiplodia, respectivamente. Para produção do inóculo dos patógenos, os isolados foram cultivados em meio BDA por 10 dias, sob fotoperíodo de 12 horas. As placas com as colônias de $C$. gloeosporioides foram inundadas com água destilada e raspadas com alça de Drigalski para se obter uma suspensão de esporos. Discos de micélio de $L$. theobromae foram depositados sobre fragmentos da casca de abacates, previamente autoclavados, depositados sobre meio de cultura ágar-água. Após 
10 dias de incubação a $25^{\circ} \mathrm{C}$ e fotoperíodo de 12 horas, esporos foram retirados dos cirros formados em picnídios sobre as cascas de abacate. A concentração de conídios nas suspensões dos patógenos foram estimadas com hemacitômetro e ajustadas para $10^{5}$ conídios $\mathrm{mL}^{-1}$.

$\mathrm{Na}$ inoculação de $C$. gloeosporioides, a região equatorial do fruto foi raspada com uma lixa de unha de papelão, ocasionando um ferimento superficial de aproximadamente $0,5 \times 0,5 \mathrm{~cm}$, seguida da deposição de $40 \mu \mathrm{L}$ da suspensão de esporos sobre o ferimento. Para a inoculação de $L$. theobromae foram depositados $60 \mu \mathrm{L}$ da suspensão de esporos sobre a região peduncular, sem a realização de ferimento prévio. Os frutos inoculados foram mantidos a $25^{\circ} \mathrm{C}$ por $24 \mathrm{~h}$ de câmara úmida, realizada com umidificador, antes de serem tratados com UV-C, enquanto os frutos não inoculados foram tratados com UV-C logo após a desinfetação com oxicloreto de cálcio.

Os tratamentos com UV-C foram feitos com frutos acondicionados em bandeja compartimentalizada (bandeja de ovos), expondo a região peduncular e/ou equatorial do fruto à radiação UV-C por $0,15,20,25$ e 30 segundos. A distância dos frutos à fonte de radiação UV-C foi de $8 \mathrm{~cm}$ e $13 \mathrm{~cm}$, em relação ao pedúnculo e à região equatorial, respectivamente. Nos frutos não inoculados, a exposição à radiação UV-C foi na região do pedúnculo e em dois lados opostos da região equatorial. Frutos inoculados com $L$. theobromae foram tratados com UV-C no pedúnculo, $\mathrm{e}$ os frutos inoculados com $C$. gloeosporioides foram tratados na região equatorial inoculada e na região oposta equatorial não incoculada. A dose de radiação variou em função do tempo de exposição e da distância entre a fonte de luz e a superfície irradiada. A partir de medições feitas com radiômetro, determinou-se a dose de radiação $\left(\mathrm{kJ} \mathrm{m}^{-2}\right)$ na distância de $8 \mathrm{~cm}$ e nos tempos $15,20,25$ e 30 segundos, como sendo de 0,$36 ; 0,48$; 0,60 e $0,72 \mathrm{~kJ} \mathrm{~m}^{-2}$, respectivamente, e na distância de $13 \mathrm{~cm}$, nos mesmos tempos, as doses foram de 0,$34 ; 0,45 ; 0,56$ e $0,67 \mathrm{~kJ} \mathrm{~m}^{-2}$.

Após os tratamentos com UV-C, os frutos foram armazenados em câmara fria a $6{ }^{\circ} \mathrm{C}$ e $85 \%$ de umidade relativa (UR) durante 21 dias. Posteriormente foram armazenados a $21{ }^{\circ} \mathrm{C}$ e $85 \%$ UR por seis (experimento 1, de frutos colhidos em abril de 2017) ou oito (experimento 2, de frutos colhidos em junho de 2017) dias, quando mais de $70 \%$ dos frutos estavam aparentemente no ponto de consumo, representado principalmente pela mudança de coloração da casca do fruto. A avaliação da incidência das doenças nos tratamentos sem inoculação dos patógenos foi realizada pelos sintomas característicos das doenças e pelos esporos dos patógenos, produzidos na superfície dos frutos e observados com auxílio de um microscópio óptico. Nos frutos inoculados, avaliou-se a incidência e a severidade das doenças, medindo-se o diâmetro e o comprimento da lesão da antracnose e da podridão peduncular, respectivamente. No dia da colheita dos frutos e ao término das avaliações das doenças, foram avaliadas as variáveis físico-químicas firmeza da polpa (Newton), sólidos solúveis ( ${ }^{\circ}$ Brix) e acidez titulável (\% ácido cítrico) nos frutos não inoculados da primeira repetição do experimento.

$\mathrm{O}$ delineamento experimental foi o inteiramente casualizado, com cinco repetições de 20 frutos por parcela, para os experimentos de incidência das doenças e de severidade da antracnose e da podridão peduncular, e de cinco frutos por parcela, para as variáveis físico-químicas. Os experimentos de incidência de doenças e de severidade de antracnose foram repetidos uma vez, sendo realizada uma análise conjunta dos experimentos 1 e 2. Para analisar o efeito dos tratamentos nas doenças e nas variáveis físico-químicas dos frutos foi realizada análise de variância, e as médias de tratamentos comparadas pelo teste de Tukey a $5 \%$ de probabilidade.

\section{RESULTADOS E DISCUSSÃO}

Durante os 21 dias de armazenamento dos abacates a $6{ }^{\circ} \mathrm{C}$ não foi observado desenvolvimento de doenças, mesmo em frutos inoculados com $C$. gloeosporioides e L. theobromae. Segundo Dann et al. (2013), a refrigeração $\left(4-7{ }^{\circ} \mathrm{C}\right)$ de avocados constitui em eficiente método de conservação em função do atraso no desenvolvimento das podridões. A respiração dos frutos é reduzida drasticamente com a redução da temperatura, retardando o amadurecimento e, consequentemente, aumentando seu período de armazenamento (DAIUTO et al., 2013). Com a mudança de temperatura para $21^{\circ} \mathrm{C}$, promoveu-se o amadurecimento dos frutos, com os mesmos atingindo o ponto de consumo aos seis ou oito dias nesta temperatura. A ocorrência das doenças pós-colheita foi constatada a partir do segundo dia a $21{ }^{\circ} \mathrm{C}$, sendo observado um incremento acentuado nos dois dias finais de armazenamento. Sintomas característicos de podridões manifestam principalmente nos últimos estágios do amadurecimento (PÉREZ-JIMÉNEZ, 2008), uma vez que compostos antifúngicos presentes na casca dos frutos decrescem durante o amadurecimento, ativando infecções latentes e resultando em sintomas nos frutos rapidamente (NELSON, 2008).

A incidência de frutos com podridões nas parcelas testemunhas foi elevada: $33 \%$ e $57 \%$ nos frutos coletados em abril e junho de 2017, respectivamente (Tabela 1), o que evidenciou uma 
alta pressão de inóculo dos patógenos e uma baixa eficiência do manejo fitossanitário nos pomares e do sanitizante (oxicloreto de cálcio) usado em póscolheita.

As doses de radiação UV-C aplicadas na região equatorial e peduncular dos abacates não reduziram a incidência de frutos doentes inoculados, assim como das doenças incidentes (antracnose, podridão de lasiodiplodia e de fusicoccum) em abacates não inoculados com os patógenos, nas duas repetições do experimento (Tabela 1). Contudo, maior incidência de frutos doentes e com antracnose foi observada no segundo experimento, instalado com abacates colhidos em junho, em função, possivelmente, do aumento da fonte de inóculo nos frutos que permaneceram mais tempo nas árvores e do estádio de maturação mais avançado destes frutos no momento da colheita, atingindo o ponto de consumo aos seis dias a $21^{\circ} \mathrm{C}$, enquanto os frutos colhidos em abril atingiram aos oito dias. Segundo ValdebenitoSanhueza (2002), a menor permanência das maçãs no campo garante um menor período de exposição à pressão de inóculo e, consequentemente, uma baixa incidência da podridão olho-de-boi. A severidade da podridão peduncular da manga (OLIVEIRA et al., 2008) assim como a suscetibilidade de bananas à antracnose (PESSOA et al., 2007) são significativamente maiores em estádios de maturação mais avançados, enquanto que bananas verdes ou em estádio inicial de maturação apresentam maior resistência a infecção. Chillet et al. (2006) demonstraram que a idade fenológica é um fator chave na suscetibilidade da banana ao $C$. musae. Geralmente, frutas verdes são mais resistentes a fitopatógenos, devido à presença de fitoalexinas e outros compostos em maior quantidade (CHITARRA, CHITARRA, 2005).

Tabela 1. Incidência (\%) de doenças pós-colheita em abacates 'Hass' tratados com diferentes doses de radiação UV-C, após 21 dias de armazenamento a $6{ }^{\circ} \mathrm{C}$ seguidos de mais oito dias (experimento 1) ou seis dias (experimento 2 ) de armazenamento a $21^{\circ} \mathrm{C}, 85 \%$ UR

\begin{tabular}{|c|c|c|c|c|c|c|}
\hline \multirow{3}{*}{$\begin{array}{c}\text { Dose de } \\
\text { Radiação } \\
\left(\mathrm{KJ} \mathrm{m}^{-2}\right)^{1}\end{array}$} & \multirow{2}{*}{\multicolumn{2}{|c|}{$\begin{array}{c}\text { Frutos doentes } \\
\text { (Antracnose+Podridões) }\end{array}$}} & \multicolumn{4}{|c|}{ Doenças } \\
\hline & & & \multicolumn{2}{|c|}{ Antracnose } & \multirow{2}{*}{$\begin{array}{l}\text { Podridão de } \\
\text { lasiodiplodia }\end{array}$} & \multirow{2}{*}{$\begin{array}{l}\text { Podridão de } \\
\text { fusicoccum }\end{array}$} \\
\hline & Exp.1 & Exp. 2 & Exp.1 & Exp. 2 & & \\
\hline 0 & 33,0 & 57,0 & $29,0 \mathrm{a}$ & 55,0 & 3,5 & 1,5 \\
\hline $0,34 / 0,36$ & 33,0 & 57,0 & 29,0 & 51,0 & 4,0 & 3,0 \\
\hline $0,45 / 0,48$ & 29,0 & 55,0 & 25,0 & 48,0 & 4,5 & 2,5 \\
\hline $0,56 / 0,60$ & 32,0 & 59,0 & 22,0 & 56,0 & 6,0 & 2,5 \\
\hline $0,67 / 0,72$ & 36,0 & 47,0 & 30,0 & 38,0 & 5,0 & 2,5 \\
\hline Média $^{2}$ & $32,6 \mathrm{~A}$ & $55,0 \mathrm{~B}$ & $27,0 \mathrm{~A}$ & $49,6 \mathrm{~B}$ & 4,6 & 2,4 \\
\hline $\mathrm{CV}(\%)$ & 32,7 & 17,8 & 34,8 & 23,2 & 35,9 & 34,3 \\
\hline F (Trat.) & \multicolumn{2}{|c|}{$0,3 \mathrm{~ns}$} & \multicolumn{2}{|c|}{$0,4 \mathrm{~ns}$} & $0,3 \mathrm{~ns}$ & $0,6 \mathrm{~ns}$ \\
\hline F (Exp.) & \multicolumn{2}{|c|}{$59,3 * *$} & \multicolumn{2}{|c|}{$28,8 * *$} & $1,0 \mathrm{~ns}$ & $1,05 \times 10^{-12} \mathrm{~ns}$ \\
\hline F (Trat. X Exp.) & \multicolumn{2}{|c|}{$1,0 \mathrm{~ns}$} & \multicolumn{2}{|c|}{$2,0 \mathrm{~ns}$} & $1,6 \mathrm{~ns}$ & $0,5 \mathrm{~ns}$ \\
\hline
\end{tabular}

${ }^{1}$ Radiação exposta na região equatorial (dois lados) / radiação exposta na região peduncular.

${ }^{2}$ Médias (Frutos doentes ou Antracnose) seguidas pela mesma letra maiúscula na linha não diferem entre si pelo teste de Tukey $(\mathrm{p}<0,05)$; ** - significativo pelo teste $\mathrm{F}(\mathrm{p} \leq 0,01)$; ns - não significativo pelo teste $\mathrm{F}(\mathrm{p}>0,05)$.

A podridão de lasiodiplodia e de fusicocum foram menos frequentes com incidências médias inferiores a 5\%, não havendo diferenças entre os tratamentos e experimentos (Tabela 1). Baixa incidência da podridão peduncular, causada por $L$. theobromae e Fusicoccum spp., também foi relatada por Fischer et al. (2011) em levantamento no Estado de São Paulo, contudo, em alguns pomares no Chile a incidência da doença atingiu valores superiores a 20\% (SOTO, 2015).

Em frutos inoculados com C. gloeosporioides, não se observou efeito da radiação UV-C e de experimentos na incidência da antracnose, com média de 78 e $22 \%$ de frutos doentes e que não desenvolveram a doença, respectivamente (Tabela 2). A escolha do método de inoculação adotado no presente estudo baseou-se em experimento preliminar em que não ocorreu desenvolvimento da antracnose em frutos inoculados sem ferimento e pelo fato da inoculação através de ferimento com agulha histológica, perfurando o fruto a $2 \mathrm{~mm}$ de profundidade, ser considerado muito agressivo, com $100 \%$ de incidência da doença. Embora tenha sido observado efeito da radiação UV-C na dose 0,45 $\mathrm{KJm}^{-2}$ na severidade da antracnose, a eficácia não se confirmou no experimento 2 (Tabela 2). O tratamento de mamões com UV-C de 0,2 a $2,4 \mathrm{~kJ} \mathrm{~m}^{-}$ 2 após 10 horas da inoculação $\operatorname{com} C$. gloeosporioides também foi ineficiente no controle da antracnose, embora estas mesmas doses de UV-C tenham apresentado efeito germicida in vitro sobre o fitopatógeno (CIA et al., 2007). A radiação UV-C foi considerada eficiente no controle da podridão-dauva-madura em bagas inoculadas com $C$. gloeosporioides, duas horas antes da aplicação da radiação UV-C, com doses entre 1,05 e $8,35 \mathrm{~kJ} \mathrm{~m}^{-2}$, enquanto a radiação UV-C foi ineficiente na redução da incidência de podridões nos cachos não inoculados ou sobre as bagas adjacentes às inoculadas, podendo-se inferir que o efeito 
germicida da radiação UV-C foi melhor sobre o controle de infecções quiescentes (CIA et al., 2009). patógeno em ferimentos superficiais do que no

Tabela 2. Incidência e severidade de antracnose em abacates 'Hass' tratados com diferentes doses de radiação UV-C na região equatorial do fruto (dois lados), após 21 dias de armazenamento a $6{ }^{\circ} \mathrm{C}$ seguidos de mais oito dias (experimento 1 ) ou seis dias (experimento 2) de armazenamento a $21^{\circ} \mathrm{C}, 85 \%$ UR.

\begin{tabular}{|c|c|c|c|}
\hline \multirow{2}{*}{$\begin{array}{l}\text { Dose de radiação } \\
\qquad\left(\mathrm{KJ} \mathrm{m}^{-2}\right)^{1}\end{array}$} & \multirow{2}{*}{$\begin{array}{c}\text { Incidência } \\
(\%)\end{array}$} & \multicolumn{2}{|c|}{ Severidade $(\mathrm{cm})^{2}$} \\
\hline & & Exp.1 & Exp.2 \\
\hline 0 & 85,3 & $2,24 \mathrm{aA}$ & $2,16 \mathrm{aA}$ \\
\hline 0,34 & 77,0 & 2,10 abA & $1,94 \mathrm{aA}$ \\
\hline 0,45 & 71,2 & $1,72 \mathrm{bA}$ & $2,02 \mathrm{aA}$ \\
\hline 0,56 & 79,3 & $2,32 \mathrm{aA}$ & $1,94 \mathrm{aB}$ \\
\hline 0,67 & 77,3 & $2,18 \mathrm{abA}$ & $1,88 \mathrm{aA}$ \\
\hline Média & 78,0 & $2,11 \mathrm{~A}$ & $1,99 \mathrm{~A}$ \\
\hline C.V.(\%) & 16,1 & 12,4 & 11,4 \\
\hline F (Trat.) & $2,1 \mathrm{~ns}$ & \multicolumn{2}{|c|}{$0,9 \mathrm{~ns}$} \\
\hline F (Exp.) & $4,9 \mathrm{~ns}$ & \multicolumn{2}{|c|}{$1,1 \mathrm{~ns}$} \\
\hline F (Trat. X Exp.) & $0,8 \mathrm{~ns}$ & \multicolumn{2}{|c|}{$2,9 *$} \\
\hline
\end{tabular}

${ }^{1}$ Radiação exposta na região equatorial (dois lados).

${ }^{2}$ Médias seguidas pela mesma letra minúscula na coluna e maiúscula na linha não diferem entre si pelo teste de Tukey $(p<0,05)$; * - significativo pelo teste $F(p \leq 0,05) ; n s$ - não significativo pelo teste $F(p>0,05)$.

Em frutos inoculados com L. theobromae, assim como para antracnose, não se observou efeito da radiação UC-V, nas dosagens testadas, no controle da podridão de lasiodiplodia, atingindo $52 \%$ de incidência média de frutos doentes e lesão média de $2,8 \mathrm{~cm}$ de comprimento (Tabela 3 ). Eficiência da luzultravioleta no controle da podridão peduncular da manga foi observada em tratamento realizado imediatamente antes da inoculação de $L$. theobromae no fruto, contudo, o tratamento deixou de ser quando a inoculação foi realizada após 12 e 24 horas do tratamento dos frutos (LINS et al., 2011).
Avaliando o número de unidades formadoras de colônias de C. gloeosporioides e de L. theobromae de manga, Nascimento et al. (2014) constataram inibição superior a $70 \%$ na dose de UV-C de $0,33 \mathrm{~kJ}$ $\mathrm{m}^{-2}$, contudo, o controle do crescimento micelial foi ineficiente em doses variando de 0,33 a $1,32 \mathrm{~kJ} \mathrm{~m}^{-2}$. Embora tenha sido constatado efeito negativo sobre o crescimento micelial de $C$. gloeosporioides na dose $5,0 \mathrm{~kJ} \mathrm{~m}^{-2}$ ou acima, Terao et al., (2014) verificaram danos na epiderme dos frutos de mangas 'Tommy Atkins' com doses acima de 5,0 kJ m com incremento na severidade de podridões.

Tabela 3. Incidência e severidade de podridão de lasiodiplodia em abacates 'Hass' tratados com diferentes doses de radiação UV-C na região peduncular, após 21 dias de armazenamento a $6{ }^{\circ} \mathrm{C}$ seguidos de mais oito dias de armazenamento a $21^{\circ} \mathrm{C}, 85 \%$ UR.

\begin{tabular}{ccc}
\hline Dose de radiação & \multicolumn{2}{c}{ Podridão de lasiodiplodia } \\
\cline { 2 - 3 }$\left(\mathrm{KJ} \mathrm{m}^{-2}\right)^{1}$ & Incidência $(\%)$ & Severidade $(\mathrm{cm})$ \\
\hline 0 & 48 & 2,6 \\
0,36 & 55 & 3,2 \\
0,48 & 54 & 2,6 \\
0,60 & 56 & 2,8 \\
0,72 & 47 & 2,7 \\
\hline Média & 52 & 2,8 \\
C.V.(\%) & 18,7 & 22,5 \\
$\mathrm{~F}$ (Trat.) & $0,92 \mathrm{~ns}$ & $0,75 \mathrm{~ns}$ \\
\hline
\end{tabular}

Danos pela UVC nos frutos podem ser variáveis e dependem da espécie. D'hallewin et al. (2000) observaram controle efetivo do bolor verde em toranjas na faixa de $0,5 \mathrm{KJ} \mathrm{m}^{-2}$, e que doses mais elevadas não aumentaram a eficiência de controle da doença e causaram injúrias na casca do fruto. Em tangerinas, radiação UV-C a $3,38 \mathrm{KJ} \mathrm{m} \mathrm{m}^{-2}$ foi fitotóxica (KINAY et al., 2005).

A ausência de controle da antracnose e das podridões pedunculares em abacate pode ser atribuída ao fato da radiação UV-C não penetrar no tecido dos frutos e, portanto, não atingir as infecções já estabelecidas (LU et al., 1993) e não ter ocorrido indução de resistência. Em contraste a estes resultados, outros autores relataram eficiência da radiação UV-C no controle de doenças quiescentes em maçã (STEVENS et al., 2005, BARTNICKI et al.; 2011), manga (TERAO et al., 2015) e citros (CANALE et al., 2011).

Com relação às doses de radiação UV-C a serem empregadas em abacates para controle das doenças pós colheita, são necessários novos estudos visando determinar os efeitos de doses maiores, os limites críticos para ocorrência de fitotoxicidade, o 
tratamento da fruta na linha de seleção e a inserção deste método no manejo integrado das doenças sob condições de menor pressão de doenças e em diferentes cultivares.

Com relação às variáveis físico-químicas dos frutos, as doses de radiação UV-C avaliadas não afetaram a firmeza da polpa e os teores de sólidos solúveis e de acidez titulável (Tabela 4). Com o amadurecimento dos frutos, observou-se uma redução acentuada na firmeza da polpa, porém sem modificações nos teores de sólidos solúveis e de acidez titulável, em relação ao dia da colheita dos frutos.

Tabela 4. Características físico-químicas de avocados tratados com luz UV-C após 21 dias de armazenamento a $6{ }^{\circ} \mathrm{C}$ seguidos de mais oito dias de armazenamento a $21^{\circ} \mathrm{C}, 85 \%$ UR.

\begin{tabular}{cccc}
\hline Dose de radiação & \multicolumn{2}{c}{ Variáveis } \\
\hline$\left(\mathrm{KJ} \mathrm{m}^{-2}\right)^{1}$ & $\begin{array}{c}\text { Firmeza da polpa } \\
(\mathrm{N})\end{array}$ & Sólidos solúveis ( ${ }^{\circ}$ Brix) & Acidez titulável (\% ác. cítrico) \\
\hline 0 & 9,5 & 10,7 & 0,095 \\
$0,34 / 0,36$ & 9,2 & 8,9 & 0,096 \\
$0,45 / 0,48$ & 8,7 & 8,7 & 0,090 \\
$0,56 / 0,60$ & 8,1 & 8,7 & 0,088 \\
$0,67 / 0,72$ & 8,1 & 8,0 & 0,098 \\
\hline Média & 8,7 & 9,0 & 0,093 \\
CV $(\%)$ & 11,5 & 11,1 & 13,0 \\
F (Trat.) & $1,16 \mathrm{~ns}$ & $2,99 \mathrm{~ns}$ & $0,34 \mathrm{~ns}$ \\
\hline
\end{tabular}

Características do avocado no dia da colheita: Firmeza: > 127N; Sólidos solúveis: 8,7ºrix; Acidez titulável: 0,09\%

${ }^{1}$ Radiação exposta na região equatorial (dois lados) / radiação exposta na região peduncular; ns - não significativo pelo teste $\mathrm{F}(\mathrm{p}>0,05)$.

Em abacates 'Hass' expostos à radiação UV-C, sendo a distância dos frutos à fonte de luz de $20 \mathrm{~cm}$ e o período de exposição de $5,10,15,20$ e $25 \mathrm{~min}$, armazenados durante 21 dias a $10 \pm 1{ }^{\circ} \mathrm{C}$ e $90 \pm 5 \%$ UR, também ocorreu redução na firmeza dos frutos, independente dos tratamentos (DAIUTO et al., 2013). Em contraste a estes resultados, outros autores reportaram para tomate (PINHEIRO et al., 2015) e morango (POMBO et al., 2009) submetidos à luz UV-C, manutenção dos valores de firmeza superiores ao tratamento controle durante o armazenamento.

Com relação aos teores de sólidos solúveis, resultados similares foram obtidos por Daiuto et al. (2013), com a manutenção ao longo do período de armazenamento em função do tratamento com UV$\mathrm{C}$, contudo, o tratamento controle apresentou alguma variabilidade, com um crescimento aos três dias e uma diminuição de forma mais pronunciada em relação aos demais tratamentos, após este período. Segundo os autores, pode ser um indicativo que o processo de senescência estava mais adiantado no tratamento controle em relação aos demais tratamentos. Fischer et al. (2011) também não constataram mudança na acidez titulável em abacates 'Hass' até o sétimo dia de armazenamento a $25{ }^{\circ} \mathrm{C}$, contudo, diferente do obtido no presente trabalho, Daiuto et al. (2013) observaram uma diminuição ao longo do período de armazenamento, exceto para o tratamento UV-C por $20 \mathrm{~min}$, que apresentou aumento de valores até o $9^{\circ}$ dia de armazenamento. Segundo os mesmos autores, a exposição durante $20 \mathrm{~min}$ à luz UVC também resultou em baixa produção de $\mathrm{CO}_{2}$ e perda de massa, suportando portanto, a hipótese de maior conservação para estes frutos, pois a redução da acidez é decorrência natural da evolução da maturação dos frutos, na qual os ácidos orgânicos são metabolizados na via respiratória e convertidos em moléculas não ácidas (CHITARRA, CHITARRA, 2005).

Resultados divergentes nos teores de sólidos solúveis e de acidez titulável de abacates 'Hass', como os observados no tratamento testemunha no presente estudo em relação aos encontrados por Daiuto et al. (2013), podem ser atribuídos às diferenças de temperatura e umidade relativa durante o período de armazenamento dos frutos.

\section{CONCLUSÕES}

Doses de radiação UV-C entre 0,34 e $0,72 \mathrm{~kJ} \mathrm{~m}^{-2}$ não reduziram a ocorrência de doenças pós-colheita em abacates 'Hass', com ou sem inoculação de $C$. gloeosporioides e $L$. theobromae, assim como não afetaram as variáveis firmeza da polpa, sólidos solúveis e acidez titulável dos frutos.

\section{AGRADECIMENTOS}

Ao engenheiro mecânico Marcos Serrano, pelo protótipo de equipamento para tratamento dos frutos e calibração das doses de UV-C, e aos responsáveis pela Fazenda Jaguacy, pela disponibilidade dos frutos.

\section{REFERENCIAS}

BARTNICKI, V.A.; VALDEBENITO-SANHUEZA, R.M.; AMARANTE, C.V.T.; CASTRO, L.A.S.; RIZZATTI, M.R.; SOUZA, J.A.V. Água aquecida e radiação UV-C no controle pós-colheita de Cryptosporiopsis perennans em maçãs. Pesquisa 
Agropecuária Brasileira, Brasília, v.45, n.2, p.124-131, 2010.

BARTNICKI, V.A.; VALDEBENITO-SANHUEZA, R.M.; AMARANTE, C.V.T.; STEFFENS, C.A. Tratamentos hidrotérmico e com radiação UV-C no controle pós-colheita da podridão olho-de-boi em uma linha comercial de seleção de maçãs. Revista Brasileira de Fruticultura, Jaboticabal, v.33, n.3, p.737-745, 2011.

CANALE, M.C.; BENATO, E.A.; CIA, P.; HADDAD, M.L.; PASCHOLATI, S.F. In vitro effect of UV-C irradiation on Guignardia citricarpa and on postharvest control of citrus black spot. Tropical Plant Pathology, Brasília, v.36, n.6, 2011.

CHILLET, M.; HUBERT, O.; RIVES, M.J.; LAPEYRE DE BELLATRE, L. Effects of the physiological age of bananas on their susceptibility to wound anthracnose due Colletotrichum musae. Plant Disease, Saint Paul, v.90, p.1181-1185, 2006.

CHITARRA, M.I.F.; CHITARRA, A.B. Pós-colheita de frutos e hortaliças: fisiologia e manuseio. 2. ed. Lavras: UFLA, 2005, 783p.

CIA, P.; PASCHOLATI, S.F.; BENATO, E.A.; CAMILI, E.C.; SANTOS, C.A. Effects of gamma and UV-C irradiation on the postharvest control of papaya anthracnose. Postharvest Biology and Technology, Amsterdam, v.43, p.366-373, 2007.

CIA, P.; BENATO, E.A.; VALENTINI, S.R.T.; ANJOS, V.D.A.; PONZO, F.S.; SANCHES, J.; TERRA, M.M. Radiação ultravioleta no controle pós-colheita de Colletotrichum gloeosporioides em uva 'Niagara Rosada'. Bragantia, Campinas, v.68, n.4, p.1009-1015, 2009.

DAIUTO, E.R, VIEITES, R.L.; TREMOCOLDI, M.A. CARVALHO, L.R.; FUMIS, J.G.F. Pós colheita do abacate 'Hass' submetido a radiação UV-C. Revista Colombiana de Ciencias Hortícolas, Bogotá, v.7, n.2, p.149-160, 2013.

DANN, E.K.; PLOETZ, R.C.; COATES, L.M. PEGG, K.G. Foliar, fruit and soil borne diseases. In: SCHAFFER, B., WOLSTENHOLME, B.N., WHILEY, A.W. (Eds.). The avocado: botany, production and uses. Wallingford: CAB Intl. Press, 2013. p. 380-423.

D'HALLEWIN, G.; SCHIRRA, M.; PALA, M.; BENYEHOSHUA, S. Ultraviolet C irradiation at $0.5 \mathrm{~kJ} . \mathrm{m}^{-2}$ reduces decay without causing damage or affecting postharvest quality of star ruby grapefruit $(C$. paradise Macf.). Journal of Agricultural and Food Chemistry, Washington, v.48, n.10, p.4571-4575, 2000.

DARVAS, J. M. Pre-harvest chemical control of postharvest avocado diseases. South African Avocado Growers' Association Year Book, Duivelskloof, v.4, p.71-73, 1981.
FISCHER, I.H.; TOZZE JÚNIOR, H.J.; ARRUDA, M.C.; MASSOLA JÚNIOR, N.S. Pós-colheita de abacates Fuerte e Hass: características físicas e químicas, danos e controle de doenças. Semina. Ciências Agrárias, Londrina, v.32, p.209-220, 2011.

FISCHER, I.H.; MORAES, M. F.; PALHARINI, M.C.A.;CRUZ, J.C.S.; FIRMINO, A.C. Ocorrência de antracnose em abacate, agressividade e sensibilidade de Colletotrichum gloeosporioides a fungicidas. Agropecuária Científica no Semiárido, Patos, v.13, n.2, p.130-137, 2017.

KINAY， P.; YILDIZ， F.; SEN， F.; YILDIZ， M.; KARACALI, I. Integration of pre- and postharvest treatments to minimize Penicillium decay of Satsuma mandarins. Postharvest Biology and Technology, Amsterdam, v.37, n.1, p.31-36, 2005.

LINS, S.R.O.; OLIVEIRA, S.M.A.; ALEXANDRE, E.R.; SANTOS, A.M.G.; OLIVEIRA, T.A.S. Controle alternativo da podridão peduncular em manga. Summa Phytopathologica, Botucatu, v.37, n.3, p.121-126, 2011.

LU, J.Y.; LUKOMBO, S.M.; STEVENS, C.; KHAN, V.A.; WILSON, C.L.; PUSEY, P.L.; CHAULTZ, E. Low dose UV and gamma radiation on storage rot and physicochemical changes in peaches. Journal of Food Quality, Westport, v.16, n.4, p.301-309, 1993.

NASCIMENTO, F.V.; SANTOS, M.C.; VALDEBENITO-SANHUEZA, R.M.V.; BARTNICKI, V.A. Hydrothermal and UV-C radiation in control of pathogens of mango and melon. Summa Phytopathologica, Botucatu, v.40, n.4, p.313-317, 2014.

NELSON, S. Anthracnose on avocado. Plant Disease, Saint Paul, v.58, p.1-6, 2008.

OLIVEIRA, T.A.S.; OLIVEIRA, S.M.A.; MICHEREFF, S.J.; CÂMARA, M.P.S.; COSTA, V.S.O.; LINS, S.R.O. Efeito do estádio de maturação, tipo de inóculo e local de inoculação na severidade da podridão peduncular em manga. Tropical Plant Pathology, Brasília, v.33, n.6, p.409-414, 2008.

PALOU, L. Control of citrus postharvest diseases by physical means. Tree and Forestry Science and Biotechnology, Ikenobo, v.2, n.2, p.127-142, 2009.

PÉREZ-JIMÉNEZ, R.M. Significant avocado diseases caused by fungi and oomycetes. The European Journal of Plant Science and Biotechnology, London, v.2, n.1, p.1-24, 2008.

PESSOA, W.R.L.S.; OLIVEIRA, S.M.A.; DANTAS, S.A.F.; TAVARES, S.C.C.H.; SANTOS, A.M.G. Efeito da temperatura e período de molhamento sobre o desenvolvimento de lesões de Colletotrichum musae em banana. Summa Phytopathologica, Botucatu, v.33, p.147-151, 2007. 
PICCININ, E.; PASCHOLATI, S.F.; DI PIERO, R.M.; BENATP, E.A. Doenças do abacateiro. In: AMORIM, L.; REZENDE, J.A.M.; BERGAMIN FILHO, A.; CAMARGO, L.E.A. (Ed.). Manual de fitopatologia: doenças das plantas cultivadas. 5.ed. São Paulo: Ceres, 2016. v.2, p.1-7.

PINHEIRO, J.; ALEGRIA, C.; ABREU, M.; GONÇALVES, E.M.; SILVA, C.L.M. Use of UV-C postharvest treatment for extending fresh whole tomato (Solanum lycopersicum, cv. Zinac) shelf-life. Journal of Food Science Technology, Ontario, v.52, n.8, p.50665074, 2015.

POMBO, M.A., DOTTO, M.; MARTINEZ, G.A.; CIVELLO, P.M. UV-C irradiation delays strawberry fruit softening and modifies the expression of genes involved in cell wall degradation. Postharvest Biology and Technology, Amsterdam, v.51, p.141-148, 2009.

SCHAFFER, B.; WOLSTENHOLME, B.N.; WHILEY, A.W. The avocado: botany, production and uses. 2.ed. Wallingford: CAB Intl. Press, 2013. 560p.

SEYMOUR, G.B.; TUCKER, G.A. Avocado. In: SEYMOUR, G.B.; TAYLOR, J.E.; TUCKER, G.A. Biochemistry of fruit ripening. London: Chapman \& Hall, 1993. p.53-76.
SILVEIRA, A. C.; AGUAYOB, E.; CHISARIC, M.; ARTÉSB, F. Calcium salts and heat treatment for quality retention of fresh-cut 'Galia' melon. Postharvest Biology and Technology, Amsterdam, v.62, n.1, p.77-84, 2011.

SOTO, S.A. Enfermedades de postcosecha de palta. In: DEFILIPPI, B.B.; FERREYRA, E. R.; RIVERA, S.S. (Ed.). Optimización de lacalidad de palta 'Hass': herramientas para enfrentar nuevos desafíos. La Cruz: Instituto de Investigaciones Agropecuarias. 2015. p.6975

STEVENS, C.; KHAN, V.A.; WILSON, C.L. The effect of fruit orientation of postharvest commodities following low dose ultraviolet light-C treatment on host induced resistance to decay. Crop Protection, Oxford, v.24, n.8, p.756-759, 2005.

TERAO, D.; CAMPOS, J.S.C.; BENATO, E.A.; HASHIMOTO, J.M. Alternative strategy on control of postharvest diseases of mango (Mangifera indicaL.) by use of low dose of ultraviolet-C irradiation, Food Engineering Reviews, Berlim, v.7, p.171-175, 2015.

VALDEBENITO-SANHUEZA， R.M. Ocorrência de Cryptosporiopsis perennans em macieiras 'Fuji' no Sul do Brasil. Summa Phytopathologica, Botucatu, v.28, n.2, p.204-206, 2002. 